\title{
Direct measurement of Bisphenol A (BPA), BPA glucuronide and BPA sulfate in a diverse and low-income population of pregnant women reveals high exposure, with potential implications for previous exposure estimates: a cross-sectional study
}

\section{CrossMark}

Roy R. Gerona ${ }^{1}$, Janet Pan ${ }^{1}$, Ami R. Zota ${ }^{1,2}$, Jackie M. Schwartz', Matthew Friesen ${ }^{1}$, Julia A. Taylor ${ }^{4}$,

Patricia A. Hunt ${ }^{3}$ and Tracey J. Woodruff ${ }^{*}$

\begin{abstract}
Background: Bisphenol A (BPA) is a ubiquitous, endocrine-disrupting environmental contaminant that increases risk of some adverse developmental effects. Thus, it is important to characterize BPA levels, metabolic fate and sources of exposure in pregnant women.

Methods: We used an improved liquid chromatography-tandem mass spectrometry (LC-MS/MS) analytic method to directly and simultaneously measure unconjugated BPA (UBPA), BPA glucuronide and BPA sulfate in the urine of a population of ethnically and racially diverse, and predominately low-income pregnant women $(n=112)$ in their second trimester. We also administered a questionnaire on dietary and non-dietary sources of exposure to BPA.

Results: We found universal and high exposure to UBPA and its metabolites: median concentrations were 0.25 , 4.67, and $0.31 \mathrm{\mu g} / \mathrm{g}$ creatinine for UBPA, BPA glucuronide, and BPA sulfate, respectively. The median Total BPA (UBPA + BPA in glucuronide and sulfate forms) level was more than twice that measured in U.S. pregnant women in NHANES 2005-2006, while $30 \%$ of the women had Total BPA levels above the 95th percentile. On average, Total BPA consisted of $71 \%$ BPA in glucuronide form, $15 \%$ BPA in sulfate form and $14 \%$ uBPA, however the proportion of BPA in sulfate form increased and the proportion of UBPA decreased with Total BPA levels. Occupational and non-occupational contact with paper receipts was positively associated with BPA in conjugated (glucuronidated + sulfated) form after adjustment for demographic characteristics. Recent consumption of foods and beverages likely to be contaminated with BPA was infrequent among participants and we did not observe any positive associations with BPA analyte levels.

(Continued on next page)
\end{abstract}

\footnotetext{
* Correspondence: tracey.woodruff@ucsf.edu

${ }^{1}$ Program on Reproductive Health and the Environment, Department of Obstetrics, Gynecology and Reproductive Sciences, University of California, Mailstop 0132, 550 16th Street, 7th Floor, San Francisco, CA 94143, USA Full list of author information is available at the end of the article
} 
(Continued from previous page)

Conclusion: The high levels of BPA analytes found in our study population may be attributable to the low-income status of the majority of participants and/or our direct analytic method, which yields a more complete evaluation of BPA exposure. We observed near-universal exposure to BPA among pregnant women, as well as substantial variability in BPA metabolic clearance, raising additional concerns for effects on fetal development. Our results are consistent with studies showing thermal paper receipts to be an important source of exposure, point to the difficulty pregnant women have avoiding BPA exposure on an individual level, and therefore underscore the need for changes in BPA regulation and commerce.

Keywords: Bisphenol A, Pregnant women, Children's environmental health, Exposure sources, Liquid chromatography-tandem mass spectrometry (LC-MS/MS)

\section{Background}

Bisphenol A (BPA) is a high production volume chemical with a broad range of applications, including resins that line food and beverage cans and fermentation tanks, polycarbonate plastics, medical devices, cigarette filters and toys [1-3]. BPA is also used as a developer in thermal paper (used for receipts and tickets) and in printing ink, and has been detected in both virgin and recycled paper goods, such as food and beverage contact paper (e.g., paper plates and napkins, cardboard boxes), newspapers and paper currency [4-10]. The State of California recently added BPA to its list of known developmental and reproductive toxicants: exposure to $\mathrm{BPA}$, particularly during pregnancy, is of public health concern because BPA possesses a variety of hormonelike actions, and animal studies have shown that in utero exposure to BPA can alter the development of a wide range of organ systems (e.g., brain, prostate, mammary gland, lung, and reproductive tract) and accelerate the onset of puberty [11-16]. Furthermore, epidemiology studies have found associations between BPA exposure and adverse reproductive health effects, such as reduced semen quality, sperm DNA damage [17-19] and oocyte maturity and normal fertilization in women undergoing IVF [20].

BPA continues to be produced and used in consumer products in large quantities (averaging $8 \mathrm{lb}$ per capita in the United States with a total of 2.3 billion pounds annually $[3,21])$, resulting in ubiquitous human exposure: more than $90 \%$ of the general and $96 \%$ of the pregnant U.S. population have measurable levels of Total BPA (unconjugated BPA (uBPA) plus its primary conjugated metabolites, BPA glucuronide and BPA sulfate) in their urine $[3,22,23]$. Higher urinary levels of Total BPA have been measured in lower socioeconomic status U.S. women and children, and lower levels in U.S. Hispanic women and children, suggesting BPA exposure varies by race/ethnicity, sex and age [23-25].

Understanding sources of BPA exposure is instrumental for identifying populations at greatest risk and for devising strategies for reducing exposure. Studies measuring BPA in food and paper products have found levels as high as $730 \mathrm{ng} / \mathrm{g}$ in food (e.g., canned green beans) [26], $26.6 \mathrm{ug} / \mathrm{g}$ in food-contact paper [10] and $42.6 \mathrm{mg} / \mathrm{g}$ in thermal receipt paper [6]. Higher urinary concentrations of Total BPA have been associated with cashier-related occupations in pregnant women [27] and the general population [28, 29], with consumption of canned vegetables, hamburgers and soda in pregnant women [25], and with consumption of soda and meals prepared outside the home in the general U.S. population [30]. Smaller intervention studies of non-pregnant populations have also identified canned soup, plastic water bottles and handling thermal paper receipts as potential important sources of exposure [31-34]. Despite the importance of characterizing BPA exposure during pregnancy and the higher Total BPA levels reported in certain socioeconomic and racial/ethnic groups [22, 24], there has been little research on exposure levels and sources of exposure in ethnically and racially diverse and low-income groups of pregnant women [24].

Most biomonitoring studies to date have estimated prenatal exposure to Total BPA indirectly, using enzyme hydrolysis to cleave glucuronide and sulfate bonds with BPA, then quantifying uBPA [35]. Due to limitations in processing methodology (i.e., incomplete enzyme hydrolysis), this indirect methodology may underestimate exposure levels. In addition, emerging research points to the need for direct quantification of BPA glucuronide and BPA sulfate concentrations when determining the health risks posed by BPA, particularly to the developing fetus. First, though not observed in one rodent study [36], in vitro studies suggest that BPA glucuronide and BPA sulfate may be deconjugated by $\beta$-Glucuronidase (highly active in the placenta and fetal liver) or estrone sulfatase, respectively, thus leading to deconjugation-conjugation cycling of BPA $[37,38]$. Second, recent science indicates that BPA glucuronide may also be biologically active [39], and this possibility for BPA sulfate has not been precluded.

In the current cross-sectional study, we employed a more sensitive and accurate analytic technique to directly and simultaneously measure uBPA, BPA glucuronide and BPA sulfate in a low-income, ethnically and racially 
diverse population of pregnant women. We also administered a comprehensive questionnaire to identify potential sources of exposure to BPA.

\section{Methods}

\section{Study population and recruitment}

We recruited pregnant women in their second trimester from the Women's Options Center (WOC) at San Francisco General Hospital (SFGH) in San Francisco, California. The WOC is an academic-based outpatient clinic that performs pregnancy terminations and serves communities from Northern and Central California. We recruited pregnant women, 18 to 45 years of age, English- or Spanishspeaking, and pregnancy gestation between 13 and 24 weeks. Because our study objectives were to understand BPA exposure and exposure sources in healthy pregnancies, patients seeking a pregnancy termination due to fetal anomalies were excluded. We identified eligible study participants by reviewing the patient's medical record only after she had 1) consulted with a trained counselor for an elective second trimester pregnancy termination procedure and 2) consented to the procedure as documentation of her intent to proceed with the elective pregnancy termination. Study protocols were approved by the University of California, San Francisco Committee on Human Research. We recruited a total of 185 participants between 2009 and 2011 and collected urine samples from 171. The integrity of 54 urine samples was potentially compromised due to a freezer malfunction, so they were not analyzed for BPA. Creatinine measurements were unavailable for 5 participants who were thus excluded, leaving a total of 112 pregnant women in the final study sample.

\section{BPA exposure questionnaire and demographic data}

To evaluate dietary and non-dietary sources of exposure, we developed a BPA exposure questionnaire based on a literature review of human exposure assessment studies and measurements of BPA in various food and consumer products $[2-4,40]$. The survey instrument included 197 questions regarding: consumption of foods and beverages that could be contaminated with BPA due to packaging or preparation; occupational and non-occupational contact with paper receipts; and knowledge and avoidance of BPA. Specifically, we asked about consumption of foods and beverages packaged in cans, cartons or paper, or served on paper plates, napkins or cups, as well as consumption of wine and beer. The survey captured both short-term (i.e., consumed "today", "yesterday") as well as long-term dietary consumption. Additional demographic and medical information collected through the questionnaire or medical record abstraction included: maternal age, gestational age of the fetus, body mass index (BMI), personal and combined household income, educational attainment, insurance status, food stamp assistance, smoking status during the past year and race/ethnicity. Seven percent of our study sample completed a self-administered questionnaire $(n=8)$ as part of the field testing of the questionnaire, while the remaining $93 \%$ completed an interview-administered questionnaire (both modalities were supported by pictures and cue-cards). The BPA exposure questionnaire is available upon request from the corresponding author.

\section{Sample collection and laboratory analysis}

A non-fasting spot urine sample was collected on the day prior to the medical procedure (before any medical interventions occurred) and after the participant completed the BPA exposure questionnaire. Urine samples were stored on ice until they were aliquoted into $5 \mathrm{ml}$ polypropylene cryovials and then stored at $-80{ }^{\circ} \mathrm{C}$ until analysis. Urinary creatinine levels were measured by the SFGH Clinical Chemistry Laboratory using the enzymatic creatinine method and the Siemens Advia 1800 autoanalyzer.

Direct analysis of BPA analytes was done by liquid chromatography-tandem mass spectrometry (LC-MS/MS). We measured uBPA, BPA glucuronide and BPA sulfate simultaneously using Agilent LC 1260-AB Sciex 5500 with electrospray ionization in the negative mode as previously described [41]. Each analyte was monitored by multiple reaction monitoring using two transitions and BPA-d16 as an internal standard: uBPA, 227.012 - 133.100 and $227.0-$ 212.1; BPA glucuronide, 402.9 - 112.9 and 402.9 - 226.9; BPA sulfate, 306.9 - 227.0 and 306.9 - 212.1; and BPA-d16, 241.0 - 142.2 and 241.0 - 222.1. Each urine sample was thawed and centrifuged at $3000 \mathrm{rpm}$ for $10 \mathrm{~min}$ before it was prepared for LC-MS/MS analysis by solid phase extraction (SPE) using Waters Oasis HLB cartridge $\left(1 \mathrm{~cm}^{3}\right)$. Each SPE cartridge was washed with 5 column volumes of methanol to eliminate its reported BPA contamination [41]. The cartridges were then activated with water before $500 \mu \mathrm{L}$ of urine was loaded. The column was washed with $5 \%$ methanol before each analyte was eluted by methanol. The methanol eluates were evaporated under a stream of nitrogen gas and reconstituted in $500 \mu \mathrm{L} 10 \%$ methanol for column injection. A $25 \mu \mathrm{L}$ aliquot of the extract was used for each of the replicate injections of the sample. Chromatographic separation of the analytes was achieved by gradient elution using water with $0.05 \%$ ammonium acetate $(\mathrm{pH}=7.8)$ as mobile phase $\mathrm{A}$ and methanol with $0.05 \%$ ammonium acetate $(\mathrm{pH}=7.8)$ as mobile phase $\mathrm{B}$. The elution gradient employed was: $0-0.5 \mathrm{~min}=30 \% \mathrm{~B}$; $1 \mathrm{~min}=75 \% \mathrm{~B} ; 4 \mathrm{~min}=100 \% \mathrm{~B} ; 4-6 \mathrm{~min}=100 \% \mathrm{~B}$; and $6.01-12 \mathrm{~min}=30 \% \mathrm{~B}$. Quantification of each analyte was done by isotope dilution method using BPA-d16 as an internal standard. During method development, we also 
measured for BPA disulfate, but did not find significant levels in urine (data not shown).

We assessed the limit of detection (LOD) for each analyte by running a series of calibration standards (0.01 $100 \mathrm{ng} / \mathrm{mL}$ ), established as the lowest concentration of the analyte that gives a signal/noise $(\mathrm{S} / \mathrm{N})$ ratio of 3 . We established the limit of quantification (LOQ) as the lowest concentration with $\mathrm{S} / \mathrm{N}$ ratio of 10 while keeping the linear regression coefficient of the standard curve $\geq 0.95$. The LODs for uBPA and BPA glucuronide were $0.05 \mathrm{ng} /$ $\mathrm{mL}$ while the LOD for BPA sulfate was $0.025 \mathrm{ng} / \mathrm{mL}$. The lower LOQ for all three analytes was $0.10 \mathrm{ng} / \mathrm{mL}$. Method recoveries for each analyte were reproducibly high both within and between runs [41]. The range of recoveries obtained for uBPA, BPA glucuronide and BPA sulfate were $90.5-96.0 \%, 87.5-91.0 \%$ and $92-97.5 \%$, respectively. For each of the analytes, the recoveries were observed at a narrow range ensuring that analytical variability would not contribute significantly to measured levels of the analyte in the samples. The ranges of method precision within run and between runs established for uBPA, BPA glucuronide and BPA sulfate were $1.5-7.0 \%$ coefficient of variation (CV), $3.0-9.5 \% \mathrm{CV}$ and $2.4-$ $7.5 \% \mathrm{CV}$, respectively.

We also tested all equipment and supplies used in the collection or storage of urine for their potential to contaminate urine specimens with BPA [41]. Specifically, we simulated sample collection, extraction and analytical run using synthetic human urine (UTAK Laboratories, Inc.). All processes and equipment were found to be free of BPA contamination (BPA $<$ LOD in all field blank testing materials).

\section{Data analysis}

We imputed samples below the LOD with $\mathrm{LOD} / \sqrt{ } 2$ [23] and all analyte concentrations were adjusted for creatinine. In calculating Total BPA (the sum total concentration of all BPA analytes), it is necessary to account for the higher mass of BPA glucuronide and BPA sulfate compared to uBPA (due to the additional glucuronide and sulfate conjugate groups, respectively). Accordingly, we calculated two metrics - BPA in glucuronide form and BPA in sulfate form - that adjusted for the additional mass of the conjugate groups as follows: we multiplied the concentration of BPA glucuronide by the ratio of the molecular weight of BPA to that of BPA glucuronide (0.5645), and the concentration of BPA sulfate by the ratio of the molecular weight of BPA to that of BPA sulfate (0.7404). We summed uBPA, BPA in glucuronide form and BPA in sulfate form to calculate Total BPA and summed BPA in glucuronide form and BPA in sulfate form to calculate BPA in conjugated form. In addition to permitting a comparison of the relative levels of each BPA analyte within a sample, BPA in glucuronide form, BPA in sulfate form, BPA in conjugated form and Total BPA are the best metrics for comparing concentrations in this study to all previous studies that measured BPA glucuronide and/or BPA sulfate using enzyme hydrolysis methods.

We calculated geometric mean (GM), geometric standard deviation (GSD), median, inter-quartile range (IQR) and 95th percentile estimates for creatinine-adjusted and unadjusted BPA analytes. Distributions of UBPA, BPA in glucuronide form and BPA in sulfate form were highly right skewed. Therefore we used non-parametric tests to examine the correlation between BPA analytes as well as their univariate association with demographic characteristics and BPA exposure sources, and we used logtransformed BPA analyte levels in all multivariable analyses.

We aggregated data from the BPA exposure questionnaire to create $15 \mathrm{BPA}$ exposure source variables that represent how recently (e.g., today, yesterday, not in past two days) a participant reported contact with each type of potential BPA exposure source (e.g., contact with paper receipts, consumption of canned and paperpackaged foods) in order to evaluate our hypothesis that recent exposure would be associated with higher levels of BPA analytes. We also generated long-term dietary exposure variables that represented the frequency and quantity of items typically consumed per week. Participants who answered "don't know" to any question on the questionnaire were grouped with the "not-exposed" category if they comprised less than $5 \%$ of the study sample. (The only question to which more than $5 \%$ of participants answered "don't know" pertained to combined household income; these 27 participants were grouped with those who chose "do not want to answer.") In addition, only 4 participants reported consuming canned foods on the day of urine collection; therefore we grouped them with participants who reported eating canned foods "yesterday." Because the identical set of BPA exposure source variables were associated with BPA in glucuronide form and BPA in sulfate form in a univariate context, we analyzed and report results for BPA in conjugated form.

For multivariable analyses of the association between log-transformed BPA analyte levels and BPA exposure sources, adjusting for demographic characteristics, we first identified demographic covariates associated with log-transformed UBPA and BPA in conjugated form via backwards stepwise regression (separate models were constructed for UBPA and BPA in conjugated form). Next, we estimated marginal geometric means (i.e., covariate-adjusted geometric means) of uBPA and BPA in conjugated form, with the largest subgroup of categorical variables serving as the baseline. Results were consistent whether we adjusted for creatinine by 
including creatinine as a covariate in the model or by using creatinine-adjusted log-transformed BPA analyte levels as the outcome variable. Therefore, we present the results of the latter approach so that crude and adjusted geometric means can be compared. Linear regression assumptions were checked for final models using normalquantile and residual versus fitted plots and Shapiro-Wilk tests for normality of standardized residuals. We also performed two sensitivity analyses by refitting final models excluding: 1) 11 subjects with creatinine levels outside the World Health Organization (WHO) inclusionary range $(30-300 \mathrm{mg} / \mathrm{L}$ ) and 2) influential data points (|residuals $\mid \geq 2.5$ ) for that model. We set the level of statistical significance at $p<0.10$ for our smaller sample size. All statistical analyses were conducted in Stata (version 12). All BPA analyte levels presented are creatinine-adjusted values unless otherwise specified (creatinine measurements ranged from 15.42 to $357.07 \mathrm{mg} / \mathrm{dL}$ ).

\section{Results}

All study participants had detectable concentrations of uBPA, BPA glucuronide or BPA sulfate in their urine (Table 1). Total BPA levels were right skewed - 38 (>30 \%) participants had Total BPA levels $\geq 10 \mu \mathrm{g} / \mathrm{g}$ creatinine, $20(>17 \%)$ had Total BPA levels $\geq 50 \mu \mathrm{g} / \mathrm{g}$ creatinine and $15(>13 \%)$ had Total BPA levels $\geq 100 \mu \mathrm{g} / \mathrm{g}$ creatinine - and highly variable, with a more than three orders of magnitude range across study participants $(\mathrm{CV}=3.4)$. Concentrations of BPA in glucuronide form were higher than other BPA forms in $85 \%$ of urine samples, whereas BPA in sulfate form was higher than other BPA forms in $5 \%$ of participants who also had higher Total BPA levels (GM = 5.7 vs. $19.4 \mathrm{ng} / \mathrm{g}$, Kruskall Wallis $p=0.07$ ). On average, Total BPA was comprised of $71 \%$ BPA in glucuronide form (standard deviation (SD) $23 \%$, median $77 \%$ ), $15 \%$ BPA in sulfate form (SD $18 \%$, median $8 \%$ ), and $14 \%$ BPA (SD $22 \%$, median $4 \%)$. However, the proportion of Total BPA in sulfate form varied by race/ethnicity (whites $16 \%$, Latinas $12 \%$, Asian/Pacific Islanders $10 \%$ and Blacks $4 \%$, Kruskall Wallis $p=0.0079)$ and increased with Total BPA levels (Spearman rho $(\rho)=0.56, p<0.0001$ ), such that BPA in sulfate form was $32 \%$ of Total BPA in women in the top quartile of Total BPA levels (Fig. 1). As Total BPA levels increased, the proportion of BPA in glucuronide form remained unchanged $(p=0.62)$ and the proportion of BPA decreased $(\rho=-0.68, p<0.0001)$ (Fig. 1). Consistent with these findings, we found that levels of BPA in glucuronide and sulfate form were highly correlated with each other $(\rho=0.83, p<0.0001)$ but not with uBPA (Additional file 1), while women with Total BPA levels above the GM had higher levels of BPA in glucuronide and sulfate forms $(p<0.0001)$ but similar levels of uBPA compared to women with Total BPA levels below the GM (Additional file 2).

Our study sample was ethnically and racially diverse and primarily low income (Table 2). African Americans were the most represented and Latina and white women each comprised approximately $25 \%$ of the sample. Sixty-five percent of participants had a 12th grade or

Table 1 Urinary levels of BPA analytes in second trimester pregnant women, Northern and Central California, 2009-2011 ( $\mathrm{n}=112$ )

\begin{tabular}{|c|c|c|c|c|c|c|c|c|}
\hline & \multirow[b]{2}{*}{$\mathrm{n}(\%)>\mathrm{LOD}^{\mathrm{a}}$} & \multirow[b]{2}{*}{ GM (GSD) } & \multicolumn{5}{|c|}{ Percentile } & \multirow[b]{2}{*}{ Range } \\
\hline & & & $5^{\text {th }}$ & $25^{\text {th }}$ & $50^{\text {th }}$ & $75^{\text {th }}$ & $95^{\text {th }}$ & \\
\hline \multicolumn{9}{|l|}{ Creatinine-adjusted $(\mu \mathrm{g} / \mathrm{g})$} \\
\hline Total BPA ${ }^{\mathrm{b}}$ & $112(100)$ & $6.16(1.77)$ & 0.61 & 1.69 & 3.97 & 13.87 & 196.65 & $0.37-1,347.50$ \\
\hline BPA & $98(88)$ & $0.21(1.39)$ & $<\mathrm{LOD}$ & 0.08 & 0.25 & 0.55 & 1.61 & $<\mathrm{LOD}-16.96$ \\
\hline BPA glucuronide & $111(99)$ & $6.77(1.90)$ & 0.60 & 2.16 & 4.67 & 15.31 & 249.76 & $<\mathrm{LOD}-2,019.33$ \\
\hline BPA in glucuronide form ${ }^{c}$ & $111(99)$ & $3.82(1.90)$ & 0.34 & 1.22 & 2.64 & 8.64 & 140.99 & $<L O D-1,139.91$ \\
\hline BPA sulfate & $84(75)$ & $0.62(2.73)$ & $<\mathrm{LOD}$ & 0.05 & 0.42 & 3.54 & 80.35 & $<\mathrm{LOD}-279.77$ \\
\hline BPA in sulfate form ${ }^{c}$ & $84(75)$ & $0.46(2.73)$ & $<L O D$ & 0.04 & 0.31 & 2.62 & 59.49 & $<\mathrm{LOD}-207.14$ \\
\hline \multicolumn{9}{|l|}{ Unadjusted (ng/mL) } \\
\hline Total BPA ${ }^{b}$ & $112(100)$ & $7.69(1.74)$ & 0.88 & 2.28 & 4.61 & 19.49 & 250.06 & $0.35-539.63$ \\
\hline BPA & $98(88)$ & $0.26(1.20)$ & $<\mathrm{LOD}$ & 0.10 & 0.29 & 0.66 & 1.51 & $<\mathrm{LOD}-4.41$ \\
\hline BPA glucuronide & $111(99)$ & $8.45(1.93)$ & 0.57 & 2.49 & 6.74 & 21.08 & 359.41 & $<\mathrm{LOD}-683.42$ \\
\hline BPA in glucuronide form ${ }^{c}$ & $111(99)$ & $4.77(1.93)$ & 0.32 & 1.41 & 3.80 & 11.90 & 202.89 & $<\mathrm{LOD}-385.79$ \\
\hline BPA sulfate & $84(75)$ & $0.77(2.71)$ & 0.04 & 0.04 & 0.49 & 5.97 & 109.24 & $0.04-271.16$ \\
\hline BPA in sulfate form ${ }^{c}$ & $84(75)$ & $0.57(2.71)$ & 0.03 & 0.03 & 0.37 & 4.42 & 80.88 & $0.03-200.77$ \\
\hline
\end{tabular}

GM geometric mean, GSD geometric standard deviation, $L O D$ limit of detection

${ }^{\mathrm{a}} \mathrm{LOD}=0.05 \mathrm{ng} / \mathrm{mL}$ for BPA and BPA glucuronide and $\mathrm{LOD}=0.025 \mathrm{ng} / \mathrm{mL}$ for BPA sulfate

${ }^{\mathrm{b}}$ Total $\mathrm{BPA}=\mathrm{BPA}+\mathrm{BPA}$ in glucuronide form + BPA in sulfate form

'BPA in glucuronide form $=$ BPA glucuronide*0.5614. BPA in sulfate form $=$ BPA sulfate* 0.7404 . The factors 0.5614 and 0.7404 are the ratios of the molecular weight of BPA to the molecular weights of BPA glucuronide and BPA sulfate, respectively 


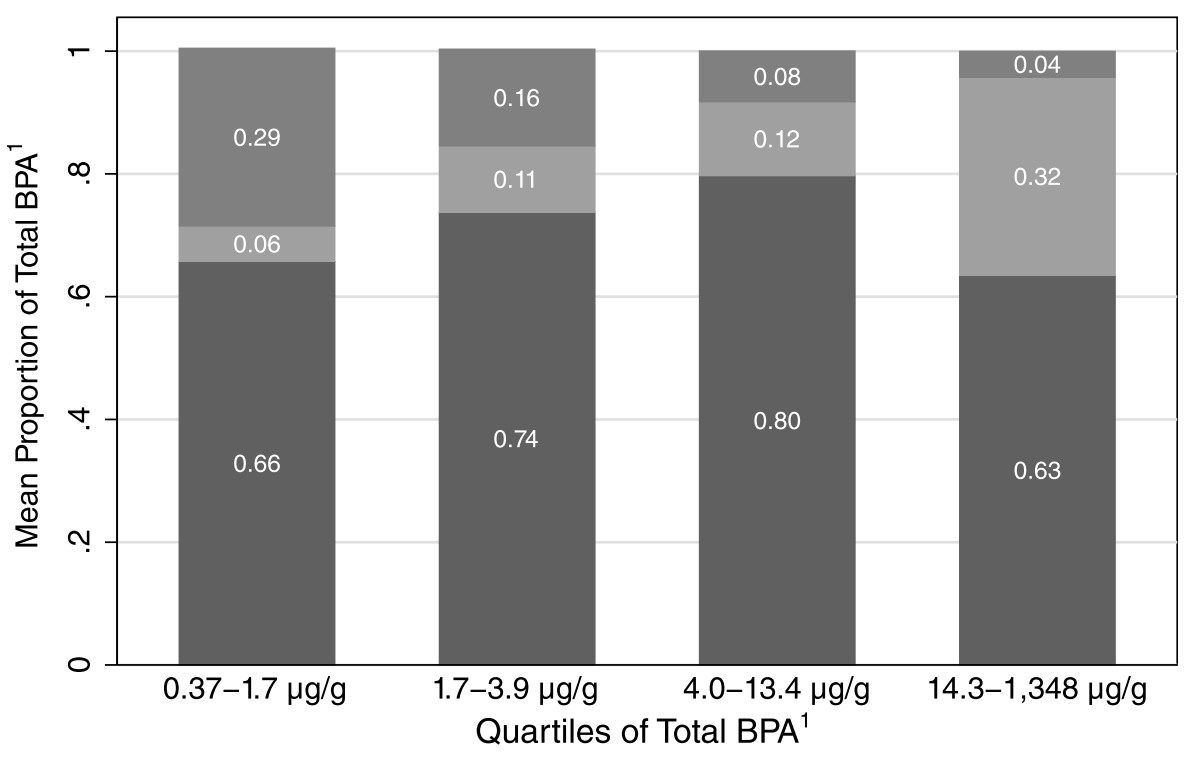

BPA in glucuronide form ${ }^{2}$

BPA in sulfate form ${ }^{2}$

UBPA

Fig. 1 Composition of Urinary Total BPA in Second Trimester Pregnant Women, by quartiles of Creatinine-Adjusted Total BPA Levels, Northern and Central California, 2009-2011 $(n=112)$. Notes: 1. Total BPA = BPA + BPA in glucuronide form + BPA in sulfate form. 2. BPA in glucuronide form $=$ BPA glucuronide*0.5614. BPA in sulfate form $=$ BPA sulfate ${ }^{*} 0.7404$. The factors 0.5614 and 0.7404 are the ratios of the molecular weight of BPA to the molecular weights of BPA glucuronide and BPA sulfate, respectively

lower education, $41 \%$ reported a combined annual household income of less than $\$ 20,000$ (only 12 subjects reported household incomes of $\$ 40,000$ or more), and nearly all women received public health insurance. BPA in conjugated form was positively associated with education and nulliparity in a univariate context, and with education and race/ethnicity in a multivariable context. UBPA was positively associated with education and negatively associated with BMI in both a univariate and multivariable context.

About half of participants reported touching or holding paper receipts on the day of urine collection and $21 \%$ held receipt-related occupations (Table 3). In contrast, only a small percentage (0-26\%) reported consuming one or more of the five potential dietary sources of BPA on the day of urine collection, which is consistent with the relatively low frequency (median $0.5-4.75$ times per week) with which participants reported consuming these foods and beverages on a regular basis (Additional file 3).

In the multivariable analysis, BPA in conjugated form was significantly associated with employment in a job that involves dermal contact with paper receipts: After adjustment for education and race/ethnicity, participants who reported handling credit card or store receipts as part of their job had more than 2-fold higher GM concentrations of BPA in conjugated form $(8.98 \mu \mathrm{g} / \mathrm{g}) \mathrm{com}-$ pared to those who did not $(4.21 \mu \mathrm{g} / \mathrm{g}, \quad p<0.10)$.
Consistent with this finding, we observed a significant positive trend between recent non-occupational contact with paper receipts and levels of BPA in conjugated form (non-parametric test for trend, $p<0.05$ ) and approximately 2-fold higher GM concentrations of BPA in conjugated form in women reporting holding or touching paper receipts the day of urine collection compared to those who did so on the day before $(p=0.08)$; however, this latter finding was no longer statistically significant when influential points were removed from the regression model. In a separate analysis to explore these findings, we observed a significant positive correlation between BPA in conjugated form and the number of times a participant reported touching receipts in the past two days $(\rho=0.29, p=0.002)$. Regarding other potential BPA exposure sources, with the exception of food processor use (positive association) and wine consumption (negative association), we did not observe any statically significant associations with BPA in conjugated form in a multivariable context.

Levels of uBPA were positively associated with education and negatively with BMI in our multivariable analysis. However, uBPA was not associated with any BPA exposure source variables in a manner consistent with our hypothesis of recent exposure leading to higher urinary uBPA analyte levels (Table 3). Levels of uBPA were lower in women who purchased more than half of their meals in both 
Table 2 Characteristics and creatinine-adjusted urinary BPA concentrations of second trimester pregnant women from Northern and Central California, 2009-2011 ( $\mathrm{n}=112)$

\begin{tabular}{|c|c|c|c|}
\hline & n (\%) & $\begin{array}{l}\text { BPA in Conjugated } \\
\text { Form }^{a}(\mu \mathrm{g} / \mathrm{g}) \\
\text { GM }(95 \% \mathrm{Cl})\end{array}$ & $\begin{array}{l}\text { BPA }(\mu \mathrm{g} / \mathrm{g}) \\
\text { GM }(95 \% \mathrm{Cl})\end{array}$ \\
\hline \multicolumn{4}{|l|}{ Ethnicity } \\
\hline Latina & $26(23)$ & $6.52(2.94,14.50)$ & $0.17(0.10,0.30)$ \\
\hline Black & $41(37)$ & $2.71(1.68,4.38)$ & $0.23(0.14,0.37)$ \\
\hline White & $27(24)$ & $8.60(3.39,21.82)$ & $0.27(0.16,0.46)$ \\
\hline Asian/PI/Unknown & $18(16)$ & $4.97(1.72,14.33)$ & $0.15(0.08,0.28)$ \\
\hline \multicolumn{4}{|l|}{ Smoking Status ${ }^{\mathrm{b}}$} \\
\hline Non-smoker & $64(60)$ & $5.48(3.37,8.90)$ & $0.20(0.14,0.28)$ \\
\hline Current smoker & $43(40)$ & $4.02(2.10,7.69)$ & $0.21(0.14,0.30)$ \\
\hline \multicolumn{4}{|l|}{ Education $^{\mathrm{b}}$} \\
\hline $11^{\text {th }}$ Grade and below & $19(18)$ & $2.26(0.96,5.36)^{* *}$ & $0.11(0.06,0.22)^{*}$ \\
\hline $12^{\text {th }}$ Grade/GED & $51(47)$ & $3.74(2.20,6.37)$ & $0.23(0.15,0.35)$ \\
\hline College or above & $38(35)$ & $10.45(5.46,20.00)$ & $0.25(0.17,0.38)$ \\
\hline \multicolumn{4}{|l|}{ Food-stamp Status } \\
\hline No & $52(46)$ & $6.46(3.82,10.93)$ & $0.23(0.15,0.34)$ \\
\hline Yes & $60(54)$ & $3.77(2.22,6.39)$ & $0.20(0.14,0.28)$ \\
\hline \multicolumn{4}{|l|}{ Parity $^{b}$} \\
\hline Nulliparous & $39(35)$ & $8.74(4.39,17.42)^{* *}$ & $0.23(0.15,0.35)$ \\
\hline Parity $\geq 1$ & $73(65)$ & $3.53(2.30,5.42)$ & $0.20(0.14,0.28)$ \\
\hline \multicolumn{4}{|c|}{ Combined Annual Household Income (\$) } \\
\hline$<20,000$ & $46(41)$ & $4.03(2.35,6.89)$ & $0.20(0.13,0.30)$ \\
\hline $20,000-40,000$ & $11(10)$ & $3.77(0.87,16.34)$ & $0.21(0.09,0.51)$ \\
\hline$>40,000$ & $13(12)$ & $16.35(4.02,66.45)$ & $0.18(0.07,0.43)$ \\
\hline Refused/Don't know & $42(37)$ & $4.34(2.37,7.94)$ & $0.23(0.15,0.36)$ \\
\hline \multicolumn{4}{|l|}{ Medi-Cal Insurance ${ }^{b}$} \\
\hline No & $20(18)$ & $5.01(2.04,12.28)$ & $0.15(0.08,0.29)$ \\
\hline \multirow[t]{2}{*}{ Yes } & $90(82)$ & $4.69(3.07,7.16)$ & $0.23(0.17,0.31)$ \\
\hline & Median (Range) & Spearman $\rho$ & Spearman $\rho$ \\
\hline Age & $25.4(18.0-45.0)$ & 0.00 & -0.05 \\
\hline BMI & $28.6(17.2-65.8)$ & -0.02 & $-0.27^{* * *}$ \\
\hline Gestational Age, weeks & $20.0(13.3-24.0)$ & 0.01 & 0.01 \\
\hline Urine Collection time & 12:50 pm (10:00 AM - 4:50 PM) & 0.04 & -0.12 \\
\hline
\end{tabular}

${ }^{\mathrm{a}} \mathrm{BPA}$ in Conjugated form $=\mathrm{BPA}$ in glucuronide form $+\mathrm{BPA}$ in sulfate form. $\mathrm{BPA}$ in glucuronide form $=\mathrm{BPA}$ glucuronide ${ }^{*} 0.5614$. $\mathrm{BPA}$ in sulfate form $=\mathrm{BPA}$ sulfate* 0.7404 . The factors 0.5614 and 0.7404 are the ratios of the molecular weight of BPA to the molecular weights of BPA glucuronide and BPA sulfate, respectively

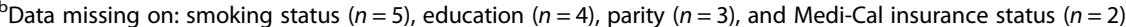

${ }^{*}=p<0.1$ and ${ }^{* *}=p<0.05$ for Kruskal-Wallis test

${ }^{* * *}=p<0.05$ for Spearman Correlation test

univariate and multivariable analyses, however this association was not significant in the sensitivity analysis models $(p=0.6$ and $p=0.35$ when influential points and creatinine levels outside WHO range were excluded, respectively).

Women who reported knowledge of BPA or taking action to avoid BPA had similar levels of uBPA and BPA in conjugated form as women who did not (Table 3). Lastly, long-term dietary exposure scores were not associated with concentrations of either uBPA or BPA in conjugated form (Additional file 4).

To confirm the high levels of BPA glucuronide we observed, we sent six urine samples with high $(n=3)$ and low $(n=3)$ levels of BPA glucuronide to the University 
Table 3 Crude and adjusted BPA analyte levels, by sources of exposure, in second trimester pregnant women from Northern and Central California, 2009-2011 ( $n=112)$

\begin{tabular}{|c|c|c|c|c|c|}
\hline \multirow{3}{*}{\multicolumn{2}{|c|}{$\begin{array}{l}\text { n (\%) } \\
\text { Job involves handling paper receipts }\end{array}$}} & \multicolumn{2}{|c|}{ BPA in Conjugated Form ${ }^{a}$ ( $\mu \mathrm{g} / \mathrm{g}$ creatinine) } & \multicolumn{2}{|c|}{ BPA ( $\mu \mathrm{g} / \mathrm{g}$ creatinine) } \\
\hline & & GM $(95 \% \mathrm{Cl})$ & MGM $(95 \%$ Cl) & GM $(95 \% \mathrm{Cl})$ & MGM (95 \% Cl) \\
\hline & & \multicolumn{4}{|c|}{ Job involves handling paper receipts } \\
\hline $\mathrm{No}^{\mathrm{d}}$ & $89(79)$ & $4.11(2.70,6.25)$ & $4.21(2.83,6.26)$ & $0.22(0.16,0.29)$ & $0.21(0.16,0.27)$ \\
\hline Yes & $23(21)$ & $9.13(4.10,20.37)^{* *}$ & $8.98(4.07,19.83)^{* * *}$ & $0.19(0.11,0.32)$ & $0.18(0.11,0.32)$ \\
\hline \multicolumn{6}{|c|}{ Touched or held paper receipts $^{\mathrm{b}}$} \\
\hline Not in past 2 days & $18(16)$ & $2.85(1.03,7.89)$ & $3.78(1.53,9.35)$ & $0.24(0.11,0.49)$ & $0.22(0.12,0.41)$ \\
\hline Yesterday & $37(33)$ & $3.57(2.00,6.35)$ & $3.40(1.84,6.27)^{* * *}$ & $0.16(0.10,0.27)$ & $0.19(0.12,0.29)$ \\
\hline Today $^{d}$ & $57(51)$ & $6.98(4.02,12.09)$ & $6.87(4.16,11.35)$ & $0.24(0.17,0.33)$ & $0.21(0.15,0.30)$ \\
\hline \multicolumn{6}{|l|}{ Drank canned drinks } \\
\hline Not in past 2 days $^{\mathrm{d}}$ & $57(51)$ & $6.32(3.83,10.41)$ & $6.24(3.81,10.24)$ & $0.21(0.14,0.31)$ & $0.20(0.14,0.28)$ \\
\hline Yesterday & $44(39)$ & $3.65(1.92,6.95)$ & $3.44(1.94,6.10)$ & $0.22(0.15,0.34)$ & $0.22(0.15,0.32)$ \\
\hline Today & $11(10)$ & $3.77(1.05,13.55)$ & $5.73(1.77,18.59)$ & $0.16(0.06,0.45)$ & $0.18(0.08,0.40)$ \\
\hline \multicolumn{6}{|l|}{ Drank cartoned drinks } \\
\hline Not in past 2 days $^{d}$ & $79(71)$ & $5.75(3.58,9.22)$ & $5.81(3.80,8.86)$ & $0.22(0.17,0.30)$ & $0.23(0.17,0.30)$ \\
\hline Yesterday & $22(20)$ & $3.72(1.78,7.78)$ & $3.73(1.61,8.64)$ & $0.23(0.12,0.44)$ & $0.16(0.09,0.30)$ \\
\hline Today & $11(10)$ & $2.38(0.90,6.33)$ & $2.32(0.68,7.95)$ & $0.11(0.03,0.32)$ & $0.13(0.06,0.28)$ \\
\hline \multicolumn{6}{|l|}{ Drank from paper cup } \\
\hline Not in past 2 days $^{d}$ & $55(49)$ & $5.55(3.19,9.66)$ & $5.53(3.35,9.14)$ & $0.22(0.16,0.32)$ & $0.25(0.18,0.35)$ \\
\hline Yesterday & $28(25)$ & $3.18(1.61,6.28)$ & $3.23(1.53,6.79)$ & $0.15(0.09,0.28)$ & $0.14(0.08,0.23)^{* * *}$ \\
\hline Today & $29(26)$ & $5.61(2.56,12.29)$ & $5.80(2.82,11.93)$ & $0.24(0.14,0.42)$ & $0.20(0.12,0.32)$ \\
\hline \multicolumn{6}{|l|}{ Ate canned foods ${ }^{c}$} \\
\hline Not in past 2 days $^{d}$ & $75(67)$ & $5.60(3.52,8.92)$ & $5.58(3.61,8.62)$ & $0.18(0.13,0.24)$ & $0.18(0.14,0.25)$ \\
\hline Yesterday or today & $37(33)$ & $3.60(1.91,6.76)$ & $3.78(2.01,7.11)$ & $0.30(0.19,0.46)$ & $0.25(0.16,0.39)$ \\
\hline \multicolumn{6}{|c|}{$\begin{array}{l}\text { Ate food served or packaged } \\
\text { in paper or cardboard }\end{array}$} \\
\hline Not in past 2 days $^{d}$ & $44(39)$ & $5.77(2.99,11.15)$ & $5.87(3.30,10.45)$ & $0.25(0.17,0.37)$ & $0.27(0.18,0.40)$ \\
\hline Yesterday & $38(34)$ & $3.45(1.94,6.14)$ & $3.57(1.92,6.63)$ & $0.16(0.10,0.25)$ & $0.15(0.10,0.23)^{* * * *}$ \\
\hline Today & $30(27)$ & $5.75(2.74,12.04)$ & $5.62(2.85,11.09)$ & $0.23(0.13,0.41)$ & $0.19(0.12,0.31)$ \\
\hline \multicolumn{6}{|c|}{ Purchases $>1 / 2$ of all meals ${ }^{b}$} \\
\hline $\mathrm{No}^{d}$ & $69(64)$ & $4.37(2.66,7.18)$ & $4.42(2.81,6.95)$ & $0.26(0.18,0.36)$ & $0.24(0.18,0.33)$ \\
\hline Yes & $38(36)$ & $5.37(2.87,10.04)$ & $5.55(2.94,10.47)$ & $0.15(0.09,0.23)^{*}$ & $0.15(0.10,0.23)^{* * *}$ \\
\hline \multicolumn{6}{|l|}{ Consumes wine $^{b}$} \\
\hline $\mathrm{No}^{\mathrm{d}}$ & $68(62)$ & $5.90(3.72,9.37)$ & $6.39(4.04,10.12)$ & $0.20(0.14,0.27)$ & $0.20(0.14,0.27)$ \\
\hline Yes & $42(38)$ & $3.20(1.71,5.99)^{* *}$ & $2.95(1.65,5.30)^{* * * *}$ & $0.24(0.15,0.39)$ & $0.22(0.15,0.33)$ \\
\hline \multicolumn{6}{|l|}{ Consumes beer } \\
\hline $\mathrm{No}^{\mathrm{d}}$ & $75(67)$ & $4.37(2.69,7.11)$ & $4.84(3.10,7.55)$ & $0.21(0.15,0.29)$ & $0.21(0.16,0.29)$ \\
\hline Yes & $37(33)$ & $5.95(3.39,10.45)$ & $5.06(2.72,9.42)$ & $0.21(0.14,0.33)$ & $0.19(0.12,0.28)$ \\
\hline \multicolumn{6}{|c|}{$\begin{array}{l}\text { Eats food stored in clear, } \\
\text { shatterproof plastic containers }\end{array}$} \\
\hline No & $38(35)$ & $4.93(2.67,9.10)$ & $5.45(2.98,9.97)$ & $0.26(0.15,0.45)$ & $0.24(0.16,0.37)$ \\
\hline$Y_{e s}^{d}$ & $70(65)$ & $4.68(2.90,7.56)$ & $4.55(2.91,7.13)$ & $0.19(0.14,0.25)$ & $0.18(0.14,0.25)$ \\
\hline \multicolumn{6}{|l|}{ Uses food processor ${ }^{b}$} \\
\hline $\mathrm{No}^{\mathrm{d}}$ & $92(84)$ & $4.43(2.94,6.67)$ & $4.23(2.89,6.20)$ & $0.23(0.17,0.31)$ & $0.21(0.16,0.28)$ \\
\hline Yes & $17(16)$ & $8.44(3.19,22.33)$ & $12.81(5.03,32.60)^{* * * *}$ & $0.14(0.08,0.26)$ & $0.18(0.09,0.34)$ \\
\hline
\end{tabular}


Table 3 Crude and adjusted BPA analyte levels, by sources of exposure, in second trimester pregnant women from Northern and Central California, 2009-2011 ( $\mathrm{n}=112)$ (Continued)

\begin{tabular}{|c|c|c|c|c|c|}
\hline \multicolumn{6}{|c|}{ Uses blender with plastic pitcher ${ }^{\mathrm{b}}$} \\
\hline $\mathrm{No}^{\mathrm{d}}$ & $82(76)$ & $5.25(3.35,8.21)$ & $5.35(3.53,8.10)$ & $0.22(0.16,0.30)$ & $0.21(0.16,0.28)$ \\
\hline Yes & $26(24)$ & $3.93(1.91,8.08)$ & $4.05(1.95,8.41)$ & $0.19(0.11,0.34)$ & $0.20(0.12,0.32)$ \\
\hline \multicolumn{6}{|l|}{$\begin{array}{l}\text { Uses kitchen appliance with } \\
\text { plastic bowl/pitcher }\end{array}$} \\
\hline $\mathrm{No}^{d}$ & $58(54)$ & $5.58(3.31,9.41)$ & $5.63(3.47,9.13)$ & $0.23(0.16,0.33)$ & $0.20(0.15,0.29)$ \\
\hline Yes & $49(46)$ & $3.92(2.24,6.84)$ & $4.02(2.35,6.88)$ & $0.19(0.13,0.29)$ & $0.20(0.14,0.29)$ \\
\hline \multicolumn{6}{|l|}{ Knows or heard about BPA ${ }^{b}$} \\
\hline $\mathrm{No}^{\mathrm{d}}$ & $65(60)$ & $3.94(2.54,6.10)$ & $4.32(2.69,6.93)$ & $0.20(0.14,0.28)$ & $0.19(0.14,0.27)$ \\
\hline Yes & $44(40)$ & $6.55(3.33,12.89)$ & $5.95(3.37,10.50)$ & $0.23(0.15,0.34)$ & $0.21(0.14,0.31)$ \\
\hline \multicolumn{6}{|l|}{ Takes action to avoid BPA } \\
\hline None $^{d}$ & $81(72)$ & $5.16(3.28,8.12)$ & $5.31(3.48,8.10)$ & $0.20(0.15,0.28)$ & $0.20(0.15,0.27)$ \\
\hline Avoids BPA or purchases & $14(12)$ & & & & \\
\hline BPA-free labeled products & & $2.16(0.85,5.48)$ & $2.48(0.90,6.85)$ & $0.30(0.15,0.62)$ & $0.25(0.12,0.51)$ \\
\hline Avoids BPA and purchases & $17(15)$ & & & & \\
\hline BPA-free labeled products & & $6.93(2.67,17.99)$ & $6.09(2.46,15.08)$ & $0.18(0.08,0.40)$ & $0.18(0.10,0.34)$ \\
\hline \multicolumn{6}{|c|}{ 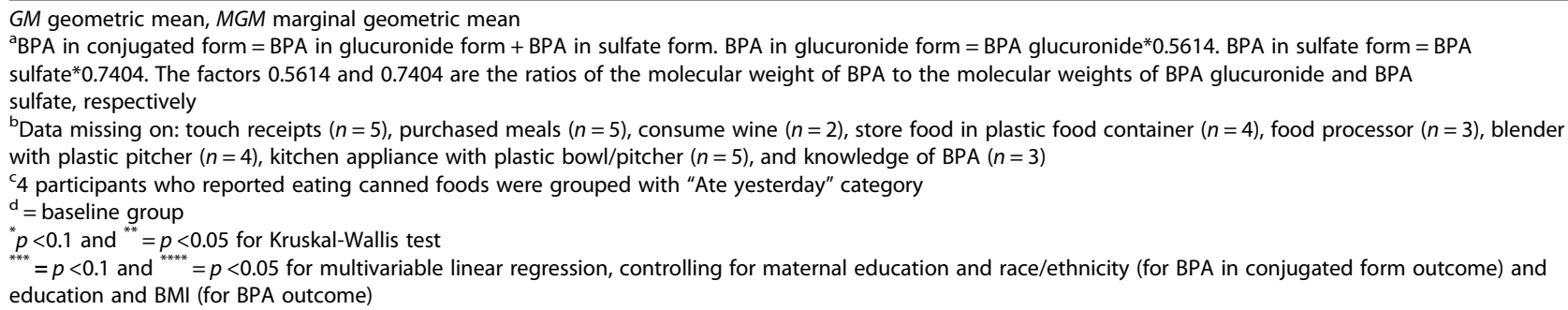 } \\
\hline
\end{tabular}

of Missouri at Columbia (blinded to our results) for direct measurement via LC-MS/MS [42]. The University of Missouri results were $100 \%$ consistent with ours in terms of distinguishing samples with high and low BPA glucuronide levels and in terms of comparative concentrations (Table 4).

\section{Discussion}

We applied an analytic method to directly, and therefore more specifically and accurately, measure urinary uBPA, BPA glucuronide, and BPA sulfate, and found universal

Table 4 University of Missouri confirmation of urinary BPA glucuronide levels in second trimester pregnant women from Northern and Central California, 2009-2011 ( $n=112)$

\begin{tabular}{lll}
\hline \multirow{2}{*}{ Sample } & \multicolumn{2}{l}{ Direct measurement of BPA glucuronide $(\mathrm{ng} / \mathrm{mL})$} \\
\cline { 2 - 3 } & University of Missouri & UCSF \\
\hline A & 2.96 & 0.80 \\
B & 6.82 & 5.95 \\
C & 14.25 & 10.22 \\
D & 221.49 & 439.56 \\
E & 332.73 & 463.70 \\
F & 1069.87 & 671.67 \\
\hline
\end{tabular}

and unprecedentedly high levels in our racially/ethnically diverse sample of primarily low-income women in their second trimester of pregnancy. The median concentration of Total BPA in our study $(4.61 \mathrm{ng} / \mathrm{mL})$ was twice the levels reported in pregnant women in the United States and other countries (range $0.7-2.7 \mathrm{ng} / \mathrm{mL}$ ) (Fig. 2) [22, 25, 27, 43, 44]. Moreover, $30 \%$ of our participants had creatinine-adjusted Total BPA levels that were higher than the 95th percentile reported among U.S. pregnant women in the 2005-2006 NHANES [22]. We also detected uBPA in greater than $85 \%$ of study participants and observed high variability in the relative proportions of UBPA and BPA metabolites detected in urine samples.

The high values of BPA glucuronide in some of our subjects were confirmed in split samples analyzed by the University of Missouri, which was blinded to our results. Our results were $100 \%$ consistent in that we both distinguished high and low BPA glucuronide levels as wel as the ranking of the BPA glucuronide levels in the samples. The differences in absolute values we observed between the two laboratories' measurements may be due to the use of different sample extraction methods and/or sources of reference and internal standards. Although 


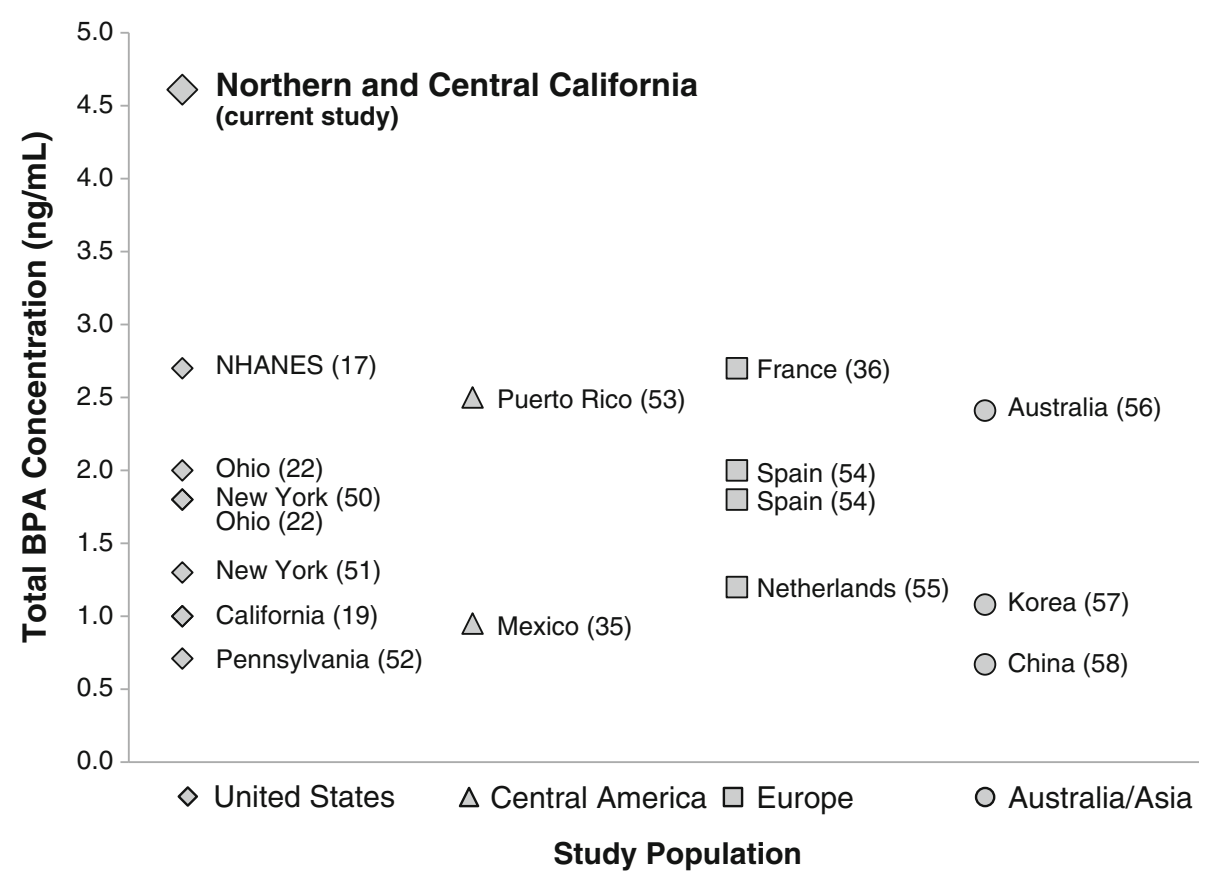

Fig. 2 Median Urinary Total BPA levels ( $\mathrm{ng} / \mathrm{mL}$ ) in studies ${ }^{1}$ of pregnant women. 1. Samples sizes: Current study, $n=112 ;$ United States (NHANES) [22], $n=86$; Massachusetts [62], $n=84$; Ohio [63], $n=244$; New York [64], $n=198 ;$ Ohio [27], $n=339 ;$ New York [65], $n=404 ;$ California [25], $n=491 ;$ Canada [66], $n=1,876$; Pennsylvania [67], $n=10$; Puerto Rico [68], $n=105$; Mexico [43], $n=60$; France [44]), $n=287$; Spain [69], $n=120 ;$ Netherlands [70], $n=100$; Australia [71], $n=26$; Korea [72], $n=757$; China [73], $n=567.2$. Total BPA =BPA + BPA in glucuronide form + BPA in sulfate form. 3.BPA in glucuronide form $=$ BPA glucuronide* 0.5614 . BPA in sulfate form $=$ BPA sulfate* 0.7404 . The factors 0.5614 and 0.7404 are the ratios of the molecular weight of BPA to the molecular weights of BPA glucuronide and BPA sulfate, respectively

both laboratories used solid phase extraction, we used different columns (our laboratory used Waters Oasis HLB SPE cartridge while the University of Missouri used Thermo Hypersep C18 SPE cartridge). Likewise, the sources of reference and internal standards differ between the two laboratories. These differences could have resulted in differences in the accuracy, precision and recovery of the methods in each laboratory. Further crossvalidation is needed to identify the exact sources of the differences in the absolute values.

Although women in the highest annual household income bracket had the highest geometric mean levels of BPA in conjugated form, our study population as a whole was predominantly low income (50\% reporting had annual household incomes $<\$ 40,000)$. Low income has been associated with higher Total BPA levels in previous studies, possibly due to differential sources of exposure [23, 24], and thus may explain, in part, the high levels of BPA analytes we observed. None of the other BPA exposure sources we investigated were significantly associated with having high (i.e., $>50 \mathrm{ng} / \mathrm{mL}$ ) levels of Total BPA (data not shown).

Our improved LC-MS/MS analytic methods could also explain the higher Total BPA levels we observed. We used LC-MS/MS to directly measure uBPA, BPA glucuronide, and BPA sulfate, whereas most previous studies used enzyme hydrolysis followed by HPLC-MS/MS [42]. The use of enzyme hydrolysis may underestimate BPA analyte levels if these reactions are incomplete or do not otherwise function as predicted, and it is plausible that this underestimation would be greatest at the highest concentrations of glucuronidated or sulfated BPA. The results of our preliminary exploration of this hypothesis indicate that the indirect method of quantification may underestimate samples with very high levels of BPA glucuronide by up to a factor of four and that, although BPA glucuronide is fully deconjugated by commercial glucuronidases, only a small fraction of it is converted to uBPA (which indirect methods use as a surrogate measure for conjugated BPA). These findings suggest that human exposure to BPA has been previously underestimated. Further studies to determine the major product formed from the deconjugation of BPA glucuronide by commercial beta-gluduronidases are underway.

Although direct measurements of BPA have been made in the general population [45], to our knowledge, this is the first study to report direct measurements of UBPA in urine of pregnant women. Our detection of uBPA in $87 \%$ of urine samples challenges prior assumptions that internal exposure to uBPA is limited due to rapid first-pass glucuronide metabolism [46, 47]. Whether the presence of uBPA in urine is due to 
incomplete metabolic clearance, dermal or inhalation exposure (which do not undergo first-pass metabolism), the deconjugation of BPA glucuronide or BPA sulfate by $\beta$-Glucuronidases or estrone sulfatase, respectively, the release of uBPA stored in tissues, other unidentified sources, or combinations thereof cannot be ascertained from our data. Nevertheless, our findings underscore the importance of obtaining a better understanding of the routes of human exposure to BPA as well as human metabolic capacity and pathways for BPA, as all of these factors have important implications for risk assessment.

We observed large variability in the relative proportions of UBPA, BPA in glucuronide form and BPA in sulfate form across study participants, with approximately $5 \%$ of the population having higher levels of BPA in sulfate form than BPA in glucuronide form. This could be due, in part, to increased activity in secondary metabolic pathways in response to the saturation of glucuronidation capacity (as seen with immature glucuronidation capacity in the fetus [48-50]): the lack of association between Total BPA and BPA in glucurondiated form, coupled with the positive correlation between Total BPA and BPA in sulfated form seen in our population, suggest that glucuronidases are either saturated or inhibited at high BPA load, thus diverting metabolism to the sulfation pathway. An additional factor that may influence BPA metabolism is polymorphisms in genes encoding glucuronidation and sulfation enzymes. Specifically, several of the primary enzymes involved in BPA glucuronidation and sulfation have functional polymorphisms that yield variants with significantly lower or higher metabolic activity [51-53]. For example, SULT 1A1, a common sulfonation enzyme of small planar phenols like BPA, is polymorphic. Its *1 allele is known to significantly sulfonate faster than its $* 2$ and $* 3$ alleles [54]. Our findings highlight the importance of quantifying the complete suite of BPA conjugates and the need for additional research on factors that influence their concentrations.

We found that women with occupations that required handling of receipts and women who recently touched paper receipts had higher levels of BPA in conjugated form. These results are consistent with the findings of Braun et al., who found a positive association between occupation as a cashier and Total BPA levels in pregnant women [27], as well as other studies of the general US population [28, 29], and Hormann et al., who demonstrated dermal and oral absorption of uBPA resulting from holding thermal receipt paper followed by consumption of hand-held food [55]. Several studies have shown that thermal paper (including that used for cash register receipts) contains miligrams per gram levels of BPA [5-8, 56-58] and that BPA can be transferred from receipts to skin and persist there even after handwashing [56]. Our results support the importance of this source of exposure to BPA and also suggest that receiptrelated exposure to BPA is not limited to those who are occupationally exposed.

Another notable finding is that participants who reported knowledge of or action to avoid BPA did not have lower levels of BPA analytes in their urine. This is consistent with a recent randomized dietary trial that concluded that education and written guidelines are insufficient to reduce BPA exposure and only federal or industrial actions can completely eliminate exposure to BPA via the food supply [59] and with the lack of awareness of thermal paper as a source of BPA exposure during the time that our study was conducted.

Unlike other U.S. studies that report the lowest Total BPA levels in Hispanic pregnant women, we found the lowest levels of Total BPA in African Americans. Our findings also did not confirm the previously reported associations between Total BPA and SES, age, smoking, or consumption of canned soup and vegetables or purchased foods [23-25, 27, 30, 33, 60, 61]. However, this could be due to lack of variability in our sample with respect to these attributes. Our study participants are predominately low income and represent a narrow age range, and although the average canned food and beverage consumption in our sample was 5.6 and 10.2 times/ week, respectively, only four participants reported consuming canned foods and 11 reported drinking canned beverages on the day of urine collection. Thus, it is likely that we lack sufficient sample size to evaluate these sources of exposure. Lastly, we relied on self-reported measures of smoking while other studies measured biomarkers of environmental tobacco smoke [27, 61], which may account for our null findings.

Our study has several limitations. Total BPA levels have been found to fluctuate during different stages of pregnancy [25] and throughout the day [27]. We collected a single spot urine sample and therefore could not account for this intra-individual variability in our evaluation of exposure sources. However, we did not observe any association between any BPA analyte (creatinine-adjusted or not) and time of urine collection previously reported in other studies of pregnant women $[25,27]$, possibly because urine was collected within a narrow time range (Table 2). Another weakness is our modest sample size and large number of investigated exposure sources. False positives may have arisen from multiple comparisons, and our results warrant confirmation in future studies.

\section{Conclusion}

Our study provides novel data on UBPA, BPA glucuronide and BPA sulfate in urine of a low-income and ethnically and racially diverse sample of pregnant women, a sizeable subset of which has substantially elevated levels. 
We observed near-universal exposure to biologically active BPA among pregnant women as well as substantial variability in BPA metabolic clearance, raising additional concerns for effects on fetal development. Our results also indicate that dermal contact with thermal paper receipts is an important source of exposure than could be mitigated. Lastly, our work points to the difficulty pregnant women have avoiding BPA exposure on an individual level and therefore underscores the need for changes that focus on the use and sources of BPA in commerce.

\section{Additional files}

Additional file 1: Spearman's correlation between creatinine-adjusted BPA analytes in Second Trimester Pregnant Women (PDF $271 \mathrm{~kb}$ )

Additional file 2: Urinary BPA analyte concentrations by log-transformed, creatinine-adjusted levels of Total BPA in Second Trimester Pregnant Women (PDF $191 \mathrm{~kb}$ )

Additional file 3: Long-term dietary exposure to potential sources of BPA, and correlation with urinary BPA in Conjugated Form 1 and UBPA in Second Trimester Pregnant Women (DOCX $21 \mathrm{~kb}$ )

Additional file 4: University of Missouri Laboratory Confirmation of BPA glucuronide: Laboratory Methods (DOCX 25 kb)

\section{Abbreviations}

BMI: body mass index; BPA: Bisphenol A; cc: cubic centimeter; CV: coefficient of variation; GM: geometric mean; GSD: geometric standard deviation; IQR: inter-quartile range; LC-MS/MS: liquid chromatography-tandem mass spectrometry; LOD: limit of detection; LOQ: limit of quantification; ng/ mL: nanogram per milliliter; NHANES: National Health and Nutrition Examination Survey; rpm: rotations per minute; SD: standard deviation; SFGH: San Francisco General Hospital; SPE: solid phase extraction; UBPA: unconjugated BPA; WHO: World Health Organization; WOC: Women's Options Center; $\mu \mathrm{g} / \mathrm{g}$ : micrograms per gram; $\mu \mathrm{L}$ : microliter; $\rho$ : Spearman rho.

\section{Competing interests}

The authors declare that they have no competing interests.

\begin{abstract}
Authors' contributions
All authors of this paper have made substantial intellectual contributions by directly participating in the planning, execution, or analysis of the study. RRG developed and performed the LC-MS/MS analysis of BPA analytes, interpreted the chemical analysis results and co-drafted the manuscript. JP performed the statistical analysis, contributed to the interpretation of data and co-drafted the manuscript. ARZ guided the statistical analysis and contributed to the interpretation of data. JMS developed the study design and instruments and contributed to data analysis/interpretation and manuscript preparation. MF performed the LC-MS/MS analysis of BPA analytes with RRG. PAH contributed to study design development and the interpretation of data. JAT performed LCMS/MS analysis of confirmation samples. TJW oversaw the research, including study design, implementation, data collection and interpretation and drafting the manuscript. All authors read and approved the final manuscript.
\end{abstract}

\section{Acknowledgements}

We thank the staff and faculty at San Francisco General Hospital Women's Options Center for assistance and support in this study. We also thank Carrie Dickenson for her coordination and implementation of the Chemical Exposures During Critical Periods of Development Study, and Katie Stephenson, Dylan Atchley and Cynthia Melgoza for their assistance in recruitment and data collection. This project was supported by the following NIH grants: P20 ES018135 (funded jointly by NIEHS and the U.S. Environmental Protection Agency, STAR RD83467801); P01 ES022841 (funded jointly by NIEHS and the U.S. Environmental Protection Agency STAR R835433); R21 ES17763; R21 ES017763 NON ARRA SUPP A112807; R01 HD021341; R01 ES013527; and K99 ES019881.

\section{Author details}

'Program on Reproductive Health and the Environment, Department of Obstetrics, Gynecology and Reproductive Sciences, University of California, Mailstop 0132, 550 16th Street, 7th Floor, San Francisco, CA 94143, USA. ${ }^{2}$ Department of Environmental and Occupational Health, Milken Institute School of Public Health, George Washington University, 950 New Hampshire Avenue NW, Suite 414, Washington, DC 20052, USA. ${ }^{3}$ School of Molecular Biosciences and Center for Reproductive Biology, Washington State University, PO Box 647521, Pullman, WA 99164-7521, USA. "Division of Biological Sciences, University of Missouri-Columbia, 114 Lefevre Hall, Columbia, MO 65211, USA.

Received: 29 October 2015 Accepted: 22 March 2016 Published online: 12 April 2016

\section{References}

1. Schecter A, Malik N, Haffner D, Smith S, Harris TR, Paepke O, et al. Bisphenol A (BPA) in U.S. food. Environ Sci Technol. 2010;44(24):9425-30. doi:10.1021/es102785d.

2. Vandenberg LN, Hauser R, Marcus M, Olea N, Welshons W. Human exposure to bisphenol A (BPA). Reprod Toxicol. 2007;24(2):139-77. doi:10.1016/j.reprotox.2007.07.010.

3. National Toxicology Program. NTP-CERHR Expert Panel Report on the Reproductive and Developmental Toxicity of Bisphenol A. Durham: Research Triangle Park; 2007.

4. Ozaki A, Yamaguchi Y, Fujita T, Kuroda K, Endo G. Chemical analysis and genotoxicological safety assessment of paper and paperboard used for food packaging. Food Chem Toxicol. 2004;42(8):1323-37. doi:10.1016/j.fct. 2004.03.010.

5. Pivnenko K, Pedersen GA, Eriksson E, Astrup TF. Bisphenol A and its structural analogues in household waste paper. Waste Manag. 2015:44:39-47. doi:10.1016/j.wasman.2015.07.017.

6. Babu S, Uppu SN, Martin B, Agu OA, Uppu RM. Unusually high levels of bisphenol A (BPA) in thermal paper cash register receipts (CRs): development and application of a robust LC-UV method to quantify BPA in CRs. Toxicol Mech Methods. 2015;25(5):410-6. doi:10.3109/ 15376516.2015.1045661.

7. Geens T, Goeyens L, Kannan K, Neels H, Covaci A. Levels of bisphenol-A in thermal paper receipts from Belgium and estimation of human exposure. Sci Total Environ. 2012;435-436:30-3. doi:10.1016/j.scitotenv.2012.07.001.

8. Liao C, Kannan K. Widespread occurrence of bisphenol A in paper and paper products: implications for human exposure. Environ Sci Technol. 2011:45(21):9372-9. doi:10.1021/es202507f.

9. Liao C, Kannan K. High levels of bisphenol A in paper currencies from several countries, and implications for dermal exposure. Environ Sci Technol. 2011;45(16):6761-8. doi:10.1021/es200977t.

10. Suciu NA, Tiberto F, Vasileiadis S, Lamastra L, Trevisan M. Recycled paper-paperboard for food contact materials: contaminants suspected and migration into foods and food simulant. Food Chem. 2013;141(4):4146-51. doi:10.1016/j.foodchem.2013.07.014.

11. Hunt PA, Koehler KE, Susiarjo M, Hodges CA, llagan A, Voigt RC, et al. Bisphenol a exposure causes meiotic aneuploidy in the female mouse. Curr Biol. 2003;13(7):546-53.

12. Vom Saal FS, Hughes $C$. An extensive new literature concerning low-dose effects of bisphenol A shows the need for a new risk assessment. Environ Health Perspect. 2005;113(8):926.

13. Cabaton NJ, Wadia PR, Rubin BS, Zalko D, Schaeberle CM, Askenase MH, et al. Perinatal exposure to environmentally relevant levels of bisphenol A decreases fertility and fecundity in CD-1 mice. Environ Health Perspect. 2011;119(4):547-52. doi:10.1289/ehp.1002559.

14. Kabuto H, Amakawa M, Shishibori T. Exposure to bisphenol A during embryonic/fetal life and infancy increases oxidative injury and causes underdevelopment of the brain and testis in mice. Life Sci. 2004;74(24):2931-40. doi:10.1016/j.lfs.2003.07.060.

15. Midoro-Horiuti T, Tiwari R, Watson CS, Goldblum RM. Maternal bisphenol a exposure promotes the development of experimental asthma in mouse pups. Environ Health Perspect. 2010;118(2):273-7. doi:10.1289/ehp.0901259.

16. Bindhumol V, Chitra KC, Mathur PP. Bisphenol A induces reactive oxygen species generation in the liver of male rats. Toxicology. 2003;188(2-3):117-24. doi:S0300483X03000568 [pii]. 
17. Li DK, Zhou Z, Miao M, He Y, Wang J, Ferber J, et al. Urine bisphenol-A (BPA) level in relation to semen quality. Fertil Steril. 2011;95(2):625-30. doi: 10.1016/j.fertnstert.2010.09.026. e1-4.

18. Meeker JD, Ehrlich S, Toth TL, Wright DL, Calafat AM, Trisini AT, et al. Semen quality and sperm DNA damage in relation to urinary bisphenol A among men from an infertility clinic. Reprod Toxicol. 2010;30(4):532-9. doi:10.1016/j. reprotox.2010.07.005.

19. Bloom MS, Vom Saal FS, Kim D, Taylor JA, Lamb JD, Fujimoto VY. Serum unconjugated bisphenol A concentrations in men may influence embryo quality indicators during in vitro fertilization. Environ Toxicol Pharmacol. 2011;32(2):319-23. doi:10.1016/j.etap.2011.06.003.

20. Fujimoto VY, Kim D, Vom Saal FS, Lamb JD, Taylor JA, Bloom MS. Serum unconjugated bisphenol A concentrations in women may adversely influence oocyte quality during in vitro fertilization. Fertil Steril. 2011;95(5):1816-9. doi:10.1016/j.fertnstert.2010.11.008.

21. U.S. Department of Commerce. Current Population Survey (CPS) Definitions. Ann Arbor: Bureau of the Census; 2010. https://www.census. gov/programs-surveys/cps.html. Accessed September 2013.

22. Woodruff TJ, Zota AR, Schwartz JM. Environmental chemicals in pregnant women in the US: NHANES 2003-2004. Environ Health Perspect. 2011;119(6):878-85.

23. Calafat AM, Ye XY, Wong LY, Reidy JA, Needham LL. Exposure of the US population to bisphenol A and 4-tertiary-octylphenol: 2003-2004. Environ Health Perspect. 2008;116(1):39-44. doi:10.1289/ehp.10753.

24. Nelson JW, Scammell MK, Hatch EE, Webster TF. Social disparities in exposures to bisphenol A and polyfluoroalkyl chemicals: a cross-sectional study within NHANES 2003-2006. Environ Health. 2012;11:10. doi:10.1186/1476-069X-11-10.

25. Quiros-Alcala L, Eskenazi B, Bradman A, Ye X, Calafat AM, Harley K. Determinants of urinary bisphenol A concentrations in Mexican/ Mexican-American pregnant women. Environ Int. 2013;59:152-60. doi:10.1016/j.envint.2013.05.016.

26. Noonan GO, Ackerman LK, Begley TH. Concentration of bisphenol A in highly consumed canned foods on the U.S. market. J Agric Food Chem. 2011;59(13):7178-85. doi:10.1021/jf201076f.

27. Braun JM, Kalkbrenner AE, Calafat AM, Bernert JT, Ye X, Silva MJ, et al. Variability and predictors of urinary bisphenol A concentrations during pregnancy. Environ Health Perspect. 2011;119(1):131-7. doi:10.1289/ehp. 1002366.

28. Hehn RS. NHANES data support link between handling of thermal paper receipts and increased urinary bisphenol a excretion. Environ Sci Technol. 2016;50(1):397-404. doi:10.1021/acs.est.5b04059.

29. Thayer KA, Taylor KW, Garantziotis S, Schurman S, Kissling GE, Hunt D, et al. Bisphenol A, Bisphenol S, and 4-Hydroxyphenyl 4-Isoprooxyphenylsulfone (BPSIP) in Urine and Blood of Cashiers. Environ Health Perspect. 2015. doi:10.1289/ehp.1409427.

30. Lakind JS, Naiman DQ. Daily intake of bisphenol A and potential sources of exposure: 2005-2006 National Health and Nutrition Examination Survey. J Expo Sci Environ Epidemiol. 2011;21(3):272-9. doi:10.1038/jes.2010.9

31. Rudel RA, Gray JM, Engel CL, Rawsthorne TW, Dodson RE, Ackerman JM, et al. Food packaging and bisphenol $A$ and bis (2-ethyhexyl) phthalate exposure: findings from a dietary intervention. Environ Health Perspect. 2011;119(7):914-20.

32. Carwile JL, Luu HT, Bassett LS, Driscoll DA, Yuan C, Chang JY, et al. Polycarbonate bottle use and urinary bisphenol A concentrations. Environ Health Perspect. 2009;117(9):1368-72. doi:10.1289/ehp.0900604.

33. Carwile JL, Ye X, Zhou X, Calafat AM, Michels KB. Canned soup consumption and urinary bisphenol A: a randomized crossover trial. JAMA. 2011;306(20): 2218-20. doi:10.1001/jama.2011.1721.

34. Ehrlich S, Calafat AM, Humblet O, Smith T, Hauser R. Handling of thermal receipts as a source of exposure to bisphenol A. JAMA. 2014;311(8):859-60. doi:10.1001/jama.2013.283735.

35. Vandenberg LN, Maffini MV, Sonnenschein C, Rubin BS, Soto AM. Bisphenol-A and the great divide: a review of controversies in the field of endocrine disruption. Endocr Rev. 2009;30(1):75-95. doi:10.1210/er.2008-0021.

36. Doerge DR, Twaddle NC, Vanlandingham M, Brown RP, Fisher JW. Distribution of bisphenol A into tissues of adult, neonatal, and fetal Sprague-Dawley rats. Toxicol Appl Pharmacol. 2011;255(3):261-70. doi:10.1016/j.taap.2011.07.009.
37. Ginsberg G, Rice DC. Does rapid metabolism ensure negligible risk from bisphenol A? Environ Health Perspect. 2009;117(11):1639.

38. Stowell $\mathrm{CL}$, Barvian KK, Young PC, Bigsby RM, Verdugo DE, Bertozzi CR, et al. A role for sulfation-desulfation in the uptake of bisphenol a into breast tumor cells. Chem Biol. 2006;13(8):891-7. doi:10.1016/j.chembiol. 2006.06.016.

39. Boucher JG, Boudreau A, Ahmed S, Atlas E. In Vitro Effects of Bisphenol A beta-D-Glucuronide (BPA-G) on Adipogenesis in Human and Murine Preadipocytes. Environ Health Perspect. 2015;123(12):1287-93. doi:10.1289/ehp.1409143.

40. Brenn-Struckhofova Z, Cichna-Markl M. Determination of bisphenol A in wine by sol-gel immunoaffinity chromatography, HPLC and fluorescence detection. Food Addit Contam. 2006;23(11):1227-35. doi:10.1080/ 02652030600654382

41. Gerona RR, Woodruff TJ, Dickenson CA, Pan J, Schwartz JM, Sen S, et al. Bisphenol-A (BPA), BPA glucuronide, and BPA sulfate in midgestation umbilical cord serum in a Northern and Central California population Environ Sci Technol. 2013;47(21):12477-85. doi:10.1021/es402764d.

42. Vandenberg LN, Gerona RR, Kannan K, Taylor JA, van Breemen RB, Dickenson CA, et al. A round robin approach to the analysis of bisphenol a (BPA) in human blood samples. Environ Health. 2014;13(1):25. doi:10.1186/1476-069X-13-25

43. Cantonwine D, Meeker JD, Hu H, Sanchez BN, Lamadrid-Figueroa $H$, Mercado-Garcia A, et al. Bisphenol a exposure in Mexico City and risk of prematurity: a pilot nested case control study. Environ Health. 2010;9:62. doi:10.1186/1476-069X-9-62.

44. Philippat C, Mortamais M, Chevrier C, Petit C, Calafat AM, Ye X, et al. Exposure to phthalates and phenols during pregnancy and offspring size at birth. Environ Health Perspect. 2012;120(3):464-70. doi:10.1289/ehp.1103634.

45. Liao C, Kannan K. Determination of free and conjugated forms of bisphenol $A$ in human urine and serum by liquid chromatography-tandem mass spectrometry. Environ Sci Technol. 2012;46(9):5003-9. doi:10.1021/ es300115a.

46. European Food Safety Authority. Opinion of the Scientific Panel on Food Additives, Flavourings, Processing Aids and Materials in Contact with Food on a request from the Commission related to 2,2-BIS(4HYDROXYPHENYL)PROPANE (Bisphenol A): Question No EFSA-Q-2005-100. EFSA J. 2006:428:1-75.

47. U.S. Food and Drug Administration (FDA). Bisphenol A (BPA): Use in Food Contact Application. Silver Spring: U.S. Food and Drug Administration (FDA): 2013. http://www.fda.gov/NewsEvents/PublicHealthFocus/ucm064437.htm. Accessed 1 December 2013.

48. Nahar MS, Liao C, Kannan K, Dolinoy DC. Fetal liver bisphenol A concentrations and biotransformation gene expression reveal variable exposure and altered capacity for metabolism in humans. J Biochem Mol Toxicol. 2013;27(2):116-23. doi:10.1002/jbt.21459.

49. Levy G, Khanna NN, Soda DM, Tsuzuki O, Stern L. Pharmacokinetics of acetaminophen in the human neonate: formation of acetaminophen glucuronide and sulfate in relation to plasma bilirubin concentration and D-glucaric acid excretion. Pediatrics. 1975;55(6):818-25.

50. Miller RP, Roberts RJ, Fischer LJ. Acetaminophen elimination kinetics in neonates, children, and adults. Clin Pharmacol Ther. 1976;19(3):284-94.

51. Court MH, Hao Q, Krishnaswamy S, Bekaii-Saab T, Al-Rohaimi A, von Moltke $\mathrm{LL}$, et al. UDP-glucuronosyltransferase (UGT) 2B15 pharmacogenetics: UGT2B15 D85Y genotype and gender are major determinants of oxazepam glucuronidation by human liver. J Pharmacol Exp Ther. 2004;310(2):656-65. doi:jpet.104.067660 [pii].

52. Menard V, Girard H, Harvey M, Perusse L, Guillemette C. Analysis of inherited genetic variations at the UGT1 locus in the French-Canadian population. Hum Mutat. 2009;30(4):677-87. doi:10.1002/humu.20946.

53. Hanioka N, Oka H, Nagaoka K, Ikushiro S, Narimatsu S. Effect of UDPglucuronosyltransferase 2B15 polymorphism on bisphenol A glucuronidation. Arch Toxicol. 2011;85(11):1373-81. doi:10.1007/s00204-011-0690-5.

54. Nagar S, Walther S, Blanchard RL. Sulfotransferase (SULT) 1A1 polymorphic variants ${ }^{*} 1,{ }^{*} 2$, and ${ }^{*} 3$ are associated with altered enzymatic activity, cellular phenotype, and protein degradation. Mol Pharmacol. 2006;69(6):2084-92. doi:10.1124/mol.105.019240.

55. Hormann AM, Vom Saal FS, Nagel SC, Stahlhut RW, Moyer CL, Ellersieck MR et al. Holding thermal receipt paper and eating food after using hand sanitizer results in high serum bioactive and urine total levels of bisphenol A (BPA). PLoS ONE. 2014;9(10):e1105-9. doi:10.1371/journal.pone.0110509. 
56. Biedermann S, Tschudin P, Grob K. Transfer of bisphenol A from thermal printer paper to the skin. Anal Bioanal Chem. 2010;398(1):571-6. doi:10.1007/s00216-010-3936-9.

57. Lu SY, Chang WJ, Sojinu SO, Ni HG. Bisphenol A in supermarket receipts and its exposure to human in Shenzhen. China Chemosphere. 2013;92(9):1190-4. doi:10.1016/..chemosphere.2013.01.096.

58. Mendum T, Stoler E, VanBenschoten H, Warner JC. Concentration of bisphenol A in thermal paper. Green Chem Lett Rev. 2011;4(1):81-6. doi:10.1080/17518253.2010.502908.

59. Sathyanarayana S, Alcedo G, Saelens BE, Zhou C, Dills RL, Yu J, et al. Unexpected results in a randomized dietary trial to reduce phthalate and bisphenol A exposures. Journal of exposure science \& environmental epidemiology. 2013;23(4):378-84. doi:10.1038/jes.2013.9.

60. Lakind JS, Naiman DQ. Bisphenol A (BPA) daily intakes in the United States: Estimates from the 2003-2004 NHANES urinary BPA data. Journal of exposure science \& environmental epidemiology. 2008. doi:10.1038/jes.2008.20.

61. He Y, Miao M, Herrinton LJ, Wu C, Yuan W, Zhou Z, et al. Bisphenol A levels in blood and urine in a Chinese population and the personal factors affecting the levels. Environ Res. 2009;109(5):629-33. doi:10.1016/j.envres. 2009.04.003.

62. Braun JM, Smith KW, Williams PL, Calafat AM, Berry K, Ehrlich S, et al. Variability of urinary phthalate metabolite and bisphenol A concentrations before and during pregnancy. Environ Health Perspect. 2012;120(5):739-45. doi:10.1289/ehp.1104139.

63. Braun JM, Kalkbrenner AE, Calafat AM, Yolton K, Ye X, Dietrich KN, et al. Impact of early-life bisphenol A exposure on behavior and executive function in children. Pediatrics. 2011;128(5):873-82. doi:peds.2011-1335 [pii].

64. Perera F, Vishnevetsky J, Herbstman JB, Calafat AM, Xiong W, Rauh V, et al. Prenatal bisphenol a exposure and child behavior in an inner-city cohort. Environ Health Perspect. 2012;120(8):1190-4. doi:10.1289/ehp.1104492.

65. Wolff MS, Engel SM, Berkowitz GS, Ye X, Silva MJ, Zhu C, et al. Prenatal phenol and phthalate exposures and birth outcomes. Environ Health Perspect. 2008;1 16(8):1092-7. doi:10.1289/ehp.11007.

66. Arbuckle TE, Marro L, Davis K, Fisher M, Ayotte P, Belanger P, et al. Exposure to free and conjugated forms of bisphenol $\mathrm{A}$ and triclosan among pregnant women in the MIREC cohort. Environ Health Perspect. 2015;123(4):277-84. doi:10.1289/ehp.1408187.

67. Martina CA, Weiss B, Swan SH. Lifestyle behaviors associated with exposures to endocrine disruptors. Neurotoxicology. 2012;33(6):1427-33. doi:10.1016/j. neuro.2012.05.016

68. Meeker JD, Cantonwine DE, Rivera-Gonzalez LO, Ferguson KK, Mukherjee B, Calafat AM, et al. Distribution, variability, and predictors of urinary concentrations of phenols and parabens among pregnant women in Puerto Rico. Environ Sci Technol. 2013;47(7):3439-47. doi:10.1021/es400510g.

69. Casas M, Valvi D, Luque N, Ballesteros-Gomez A, Carsin AE, Fernandez MF, et al. Dietary and sociodemographic determinants of bisphenol $A$ urine concentrations in pregnant women and children. Environ Int. 2013;56:10-8. doi:10.1016/i.envint.2013.02.014

70. Ye X, Pierik FH, Hauser R, Duty S, Angerer J, Park MM, et al. Urinary metabolite concentrations of organophosphorous pesticides, bisphenol A and phthalates among pregnant women in Rotterdam, the Netherlands: The Generation R study. Environ Res. 2008.

71. Callan AC, Hinwood AL, Heffernan A, Eaglesham G, Mueller J, Odland JO. Urinary bisphenol A concentrations in pregnant women. Int J Hyg Environ Health. 2013;216(6):641-4. doi:10.1016/j.ijheh.2012.10.002.

72. Lee BE, Park H, Hong YC, Ha M, Kim Y, Chang N, et al. Prenatal bisphenol A and birth outcomes: MOCEH (Mothers and Children's Environmental Health) study. Int J Hyg Environ Health. 2013. doi:10.1016/j.j.jheh.2013.07.005.

73. Chen MJ, Tang R, Ding GD, Chen XJ, Han XM, Zhou K, et al. Associations of prenatal exposure to phenols with birth outcomes. Environ Pollut. 2013:178:115-20. doi:10.1016/j.envpol.2013.03.023.

\section{Submit your next manuscript to BioMed Central and we will help you at every step:}

- We accept pre-submission inquiries

- Our selector tool helps you to find the most relevant journal

- We provide round the clock customer support

- Convenient online submission

- Thorough peer review

- Inclusion in PubMed and all major indexing services

- Maximum visibility for your research

Submit your manuscript at www.biomedcentral.com/submit
Biomed Central 